\title{
Blocking CGRP in migraine patients - a review of pros and cons
}

\author{
Marie Deen ${ }^{1 *} \mathbb{D}$, Edvige Correnti ${ }^{2 \dagger}$, Katharina Kamm $^{3 \dagger}$, Tim Kelderman $^{4 \dagger}$, Laura Papetti ${ }^{5 \dagger}$, Eloisa Rubio-Beltrán ${ }^{6 \dagger}$, \\ Simone Vigneri ${ }^{7 \dagger}$, Lars Edvinsson ${ }^{8 \dagger}$, Antoinette Maassen Van Den Brink ${ }^{6 \dagger}$ and On behalf of the European \\ Headache Federation School of Advanced Studies (EHF-SAS)
}

\begin{abstract}
Migraine is the most prevalent neurological disorder worldwide and it has immense socioeconomic impact. Currently, preventative treatment options for migraine include drugs developed for diseases other than migraine such as hypertension, depression and epilepsy. During the last decade, however, blocking calcitonin gene-related peptide (CGRP) has emerged as a possible mechanism for prevention of migraine attacks. CGRP has been shown to be released during migraine attacks and it may play a causative role in induction of migraine attacks. Here, we review the pros and cons of blocking CGRP in migraine patients. To date, two different classes of drugs blocking CGRP have been developed: small molecule CGRP receptor antagonists (gepants), and monoclonal antibodies, targeting either CGRP or the CGRP receptor. Several trials have been conducted to test the efficacy and safety of these drugs. In general, a superior efficacy compared to placebo has been shown, especially with regards to the antibodies. In addition, the efficacy is in line with other currently used prophylactic treatments. The drugs have also been well tolerated, except for some of the gepants, which induced a transient increase in transaminases. Thus, blocking CGRP in migraine patients is seemingly both efficient and well tolerated. However, CGRP and its receptor are abundantly present in both the vasculature, and in the peripheral and central nervous system, and are involved in several physiological processes. Therefore, blocking CGRP may pose a risk in subjects with comorbidities such as cardiovascular diseases. In addition, long-term effects are still unknown. Evidence from animal studies suggests that blocking CGRP may induce constipation, affect the homeostatic functions of the pituitary hormones or attenuate wound healing. However, these effects have so far not been reported in human studies. In conclusion, this review suggests that, based on current knowledge, the pros of blocking CGRP in migraine patients exceed the cons.
\end{abstract}

Keywords: Migraine, Cgrp, Cgrp receptor, Prophylactic treatment, Acute treatment, Gepants

\section{Review}

Migraine is a highly prevalent and disabling disorder for which treatment options are still inadequate. The underlying pathophysiology is largely unknown, but calcitonin gene-related peptide (CGRP) most likely plays an important role. The first time CGRP was hypothesized to be involved in migraine was in 1985 [1]. This hypothesis was later supported by the finding of CGRP release during acute migraine attacks and the subsequent

\footnotetext{
* Correspondence: mariedeen85@gmail.com

$M D, E C, K K, T K, L P, E R$, SV are Junior Fellows of EHF-SAS.

$L E, A M v d B$ are Senior Fellows of EHF-SAS.

${ }^{\dagger}$ Equal contributors

'Danish Headache Center, Department of Neurology, Rigshospitalet,

Copenhagen, Denmark

Full list of author information is available at the end of the article
}

demonstration of normalization of CGRP levels in migraine patients after efficacious sumatriptan treatment [2]. In animal studies, triptans also inhibit the release of CGRP [3]. Evidence for a causative role of CGRP in migraine came from a study showing that intravenous provocation with CGRP induces migraine-like attacks in migraine patients [4]. This led to focus on this peptide and its receptor as a possible target for new migraine therapies.

CGRP and its receptor are expressed in both the peripheral and the central nervous system (CNS), including the trigeminovascular pathways. More than 30 years ago CGRP was demonstrated in trigeminal ganglion (TG) pseudounipolar neurons [5]. These neurons connect cranial structures to the central nervous system at the lower brainstem, 
caudal part of the trigeminal nucleus caudalis and upper spinal cord at C1-C2 [6]. In the peripheral trigeminovascular system, as well as in the TG, CGRP is located in about $50 \%$ of the neurons and in unmyelinated Cfibers, whereas the CGRP receptor elements are expressed in about $40 \%$ of the TG neurons and in myelinated A-fibers, which connect the PNS with the CNS $[7,8]$. In humans, CGRP is present in two isoforms, $\alpha$-CGRP and $\beta$-CGRP, where $\alpha$-CGRP is most abundantly found in primary spinal afferents from sensory ganglia, whereas $\beta$-CGRP is mainly found in the enteric nervous system [6]. The CGRP receptor consists of three subunits: receptor activity-modifying protein 1 (RAMP1), calcitonin-like receptor (CLR) and receptor component protein (RCP) [9]. As well as playing a role in cranial nociception [10], CGRP is a potent general arterial vasodilator. At peripheral synapses, CGRP released from trigeminal terminals results in vasodilation via CGRP receptors on the smooth muscle cells of meningeal and cerebral blood vessels $[8,11]$. CGRP and its receptor are also located in the cardiovascular system where they are assumed to exert a protective role $[9,12]$.

The first designer drug able to competitively block the effect of CGRP was olcegepant [13]. This nonpeptide CGRP-receptor antagonist showed high efficacy but had a low oral bioavailability [14]. This led, however, to the synthesis of several other small molecule CGRP receptor antagonists. This class was later called the gepants. Though promising with regards to efficacy, further development of some of the gepants was discontinued due to liver toxicity upon repeated exposure [15]. Encouraged by the efficacy of blocking CGRP for the treatment of migraine, monoclonal antibodies able to block either CGRP or its receptor were developed and tested in several preclinical modalities [16, 17]. The antibodies are designer drugs that are highly specific for the target but about 500 times the size of gepants or triptans [6]. They have been designed for prophylactic use in frequent episodic and chronic migraine. In this review, we will discuss the pros and cons of blocking CGRP in migraine patients. We will review the efficacy and safety of already tested drugs and compare it to the efficacy and safety of topiramate, a widely-used migraine prophylactic. Additionally, we will review the possible consequences of blocking CGRP based on findings from animal studies. Lastly, we will discuss other concerns such as long-term use and cost of the treatment.

\section{Efficacy of CGRP (receptor) blockade: Evidence from double-blind, placebo-controlled trials}

In 2004, a proof-of-concept study showed that intravenous olcegepant was effective in the acute treatment of migraine [18]. Since then, five other gepants have been tested for the acute treatment of migraine [19-33]. Figure 1 provides an overview of the efficacy data for these agents. All gepants were significantly better than placebo at achieving their primary outcome at adequate doses: pain freedom or relief at $2 \mathrm{~h}$. Only one study, a study on safety in coronary patients, could not demonstrate difference in pain freedom at $2 \mathrm{~h}$ after telcagepant; however, only 165 of the planned 400 patients were included, reducing the statistical power of this study [27].

Five of these studies also included a comparison to a triptan $[19,21,26,29,30]$. In one of these studies, telcagepant showed a numerically higher efficacy than rizatriptan with regards to sustained pain relief [29]. In other trials, the efficacy of telcagepant, BI44370 and rimegepant showed no significant difference to that of zolmitriptan $(5 \mathrm{mg})$, eletriptan $(40 \mathrm{mg})$ and sumatriptan (100 mg), respectively [21, 26, 30]. In one large study, assessing the long-term safety of telcagepant, 19,820 attacks were treated with telcagepant and 10,981 attacks with rizatriptan. For two endpoints, pain freedom and pain relief at $2 \mathrm{~h}$, rizatriptan was superior compared to telcagepant (OR $<1$ in favor of rizatriptan. OR (95\% CI): $0.58(0.45,0.75)$ and $0.70(0.55,0.89)$, respectively). For all other pre-specified efficacy outcome measurements, no difference was found between the efficacy of telcagepant and rizatriptan at $2 \mathrm{~h} \mathrm{[19].}$

Telcagepant has also been tested as prophylactic treatment of episodic migraine [25, 28]. The first of these studies was terminated early due to adverse events and the prespecified analyses could not be performed. However, posthoc analysis showed telcagepant to be effective at four weeks in reducing migraine days [25]. In the second study, in a population of patients with perimenstrual migraine, administration of telcagepant in the perimenstrual period did not result in a significant reduction in mean monthly headache days, which was the primary endpoint [28]. There was a reduction of mean monthly on-drug headache days, but the reliability of this analysis is questionable, since no correction for multiple comparisons was done.

Antibodies against CGRP or the CGRP receptor have been tested as prophylactic treatment of episodic and chronic migraine. To date, four agents have been studied in six clinical studies [31, 32, 34-37]. Figure 2 provides an overview of the efficacy data of the studies where reduction in migraine days was the primary endpoint. All monoclonal antibodies showed a significant reduction in their primary endpoint, either mean change from baseline in monthly migraine days (5 studies) or mean change in headache hours from baseline (1 study). These agents had an additional reduction over placebo of between 1 and 2.8 migraine days per month (when not considering the inefficacious lower doses of erenumab). In the study in chronic migraine, where change in headache hours was the primary outcome (data not included in the figure), the additional reduction over placebo was 22.7 and $30.4 \mathrm{~h}$ per month for the two doses tested [37]. 
Hewitt ea., 2011 (1)

Ho ea., 2008 (1)

Voss ea., 2016

Connor ea., 2011

Ho ea., 2008 (2)

Ho ea., 2010

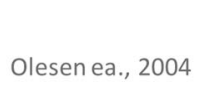

Marcus ea., 2014

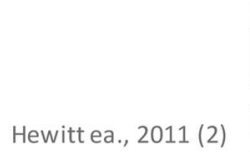

Hewitt ea., 2011 (2)

Diener ea., 2011

Connor ea., 2009

$$
\text { - }
$$

0
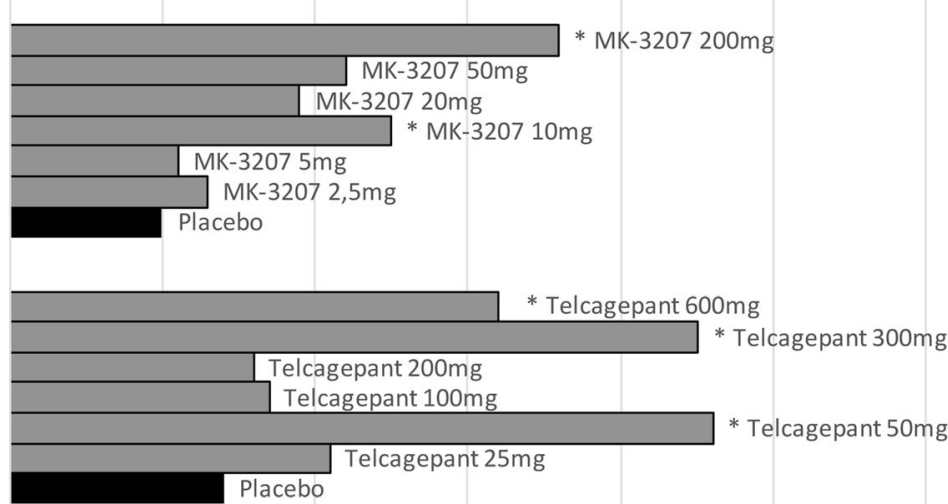

Ubrogepant 100mg
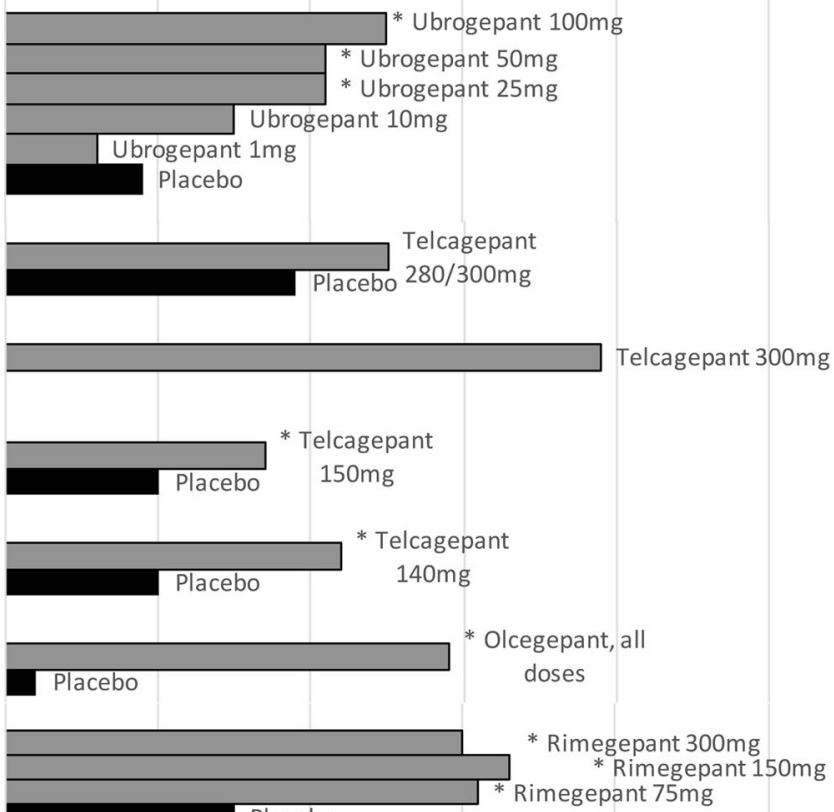

Placebo

* Telcagepant $280 \mathrm{mg}+$

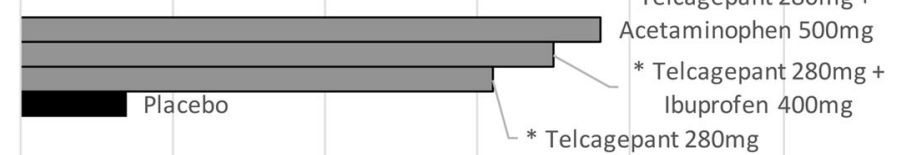

* Telcagepant 280mg

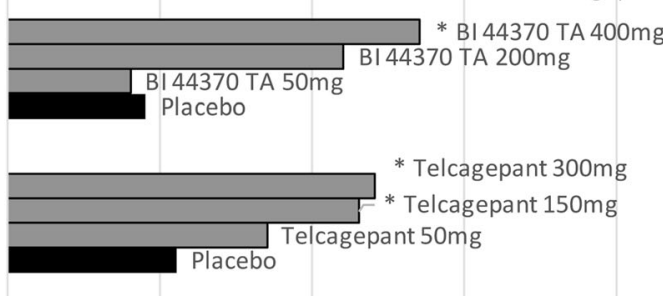

10

20

30

40

50

60

\section{Percentage of patients with pain freedom at two hours}

Fig. 1 Efficacy of gepants in the acute treatment of migraine. Bars indicated with * represents statistically significant values compared to placebo $(p<0.05)$ 


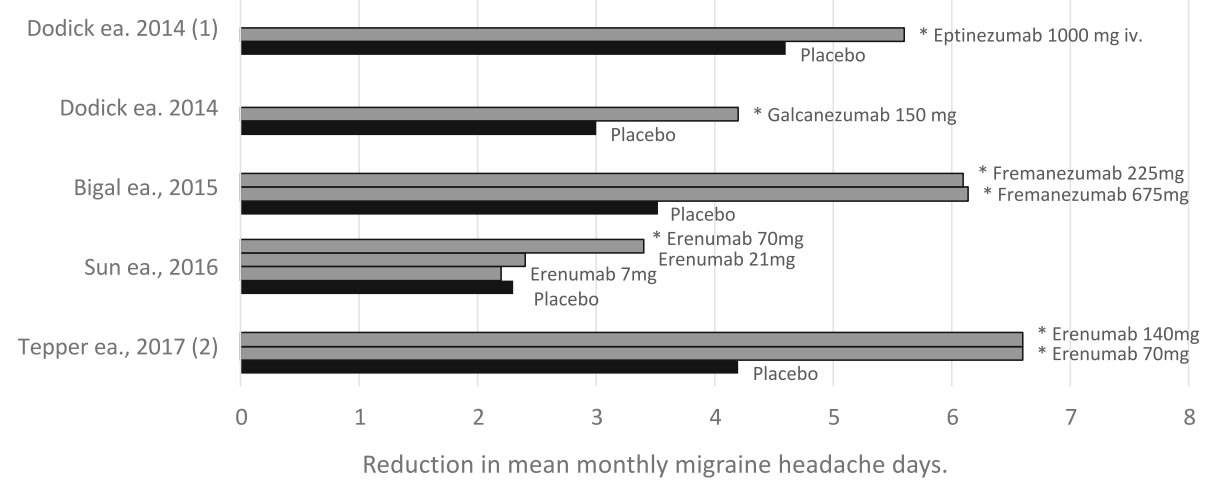

Fig. 2 Efficacy of monoclonal antibodies in the preventive treatment of migraine. Bars indicated with * represents statistically significant values compared to placebo $(p<0.05)$. (1) had change in mean monthly migraine days from baseline to weeks $5-8$ as the primary endpoint. All other studies had change in monthly migraine days from baseline to weeks 9-12 of the 12-week double-blind treatment phase as the primary endpoint. In (1) the drug/placebo was administered intravenously. In all other studies, the drug/placebo were given subcutaneously. (2) is on chronic migraine patients. All other studies are on episodic migraine patients

Interestingly, in one study, 11 of the 67 (16\%) patients who had 5 to 14 migraine days per month at baseline, experienced no migraine days during the 12 week study period, versus no patients in the placebo group [34]. In another study, 31 of 98 (32\%) patients reporting 4 to 15 migraine days at baseline had a $100 \%$ response (defined as a 28-day migraine free period over the 12-week treatment period). In the placebo group, only 18 of 104 (17\%) of placebo patients had a $100 \%$ response [35]. No other studies reported on the $100 \%$ responder rate. Although these data seem interesting, they come from post-hoc analyses and so their significance remains unclear.

The data from these 20 studies provides robust and consistent evidence for a crucial role of CGRP in migraine pathophysiology and a high efficacy of blocking CGRP as a prophylactic treatment.

\section{Is blocking CGRP as or more efficient than current preventative treatments?}

Current preventative treatment options for migraine include antihypertensive drugs, antidepressants and antiepileptic medication. In contrast to CGRP (receptor) blockers, these have all been developed for diseases other than migraine and it is estimated that less than $50 \%$ of patients on prophylactics experience a $50 \%$ reduction in their monthly attack frequency [38].

Topiramate was proven efficient as a preventative treatment of episodic migraine after positive results from three randomized, multi-center, placebo-controlled studies. Thus, topiramate is currently recommended as a level A medication for prevention of episodic migraine with established efficacy ( $\geq 2$ Class I trials) in the 2012 AHS/AAN guidelines [39]. Here, we review so far published data from Phase III studies of the monoclonal antibodies [40-43] in relation to pivotal studies on topiramate [44-48] in episodic and chronic migraine.

In three phase III studies, including over 1500 patients, topiramate $100 \mathrm{mg} / \mathrm{d}$ significantly reduced the number of monthly migraine days compared to placebo (reduction of monthly migraine days about -1.8 to -2.6 for topiramate vs. -1.0 to -1.3 for placebo). The $\geq 50 \%$ responder rates were also significantly higher for topiramate (37-54\% vs. $22-23 \%$, respectively) [44-46]. In the so far available data from Phase III studies of CGRP (receptor) antibodies, blocking of CGRP showed a similar efficacy with a reduction of monthly migraine days from baseline of -2.9 (verum) vs. -1.8 (placebo) for erenumab (AMG-334) [43]; -4.3 (300 mg)/-3.9(100 mg) vs. -3.2 (placebo) for eptinezumab (ALD-403), [41]; -4.0 (120 mg)/-3.8 (240 mg) vs. -2.15 (placebo) for galcanezumab (LY2951742) [40] and -3.7 (225 mg monthly)/ -3.4 (675 mg quarterly) vs. -2.2 (placebo) for fremanezumab (TEV-48125) [42]. The $\geq 50 \%$ responder rates were also significantly higher than for placebo and similar, albeit a little higher, to those of topiramate, ranging from $56.3 \%$ to $62.3 \%$ ( $\geq 50 \%$ responder rates: eptinezumab: $56.3 \%$ (300 mg)/ 49.8\% (100 mg) vs. 37.4\% (placebo) [41]; galcanezumab: 62.3\% (120 mg)/ 60.9\% (120 mg) vs. $38.6 \%$ (placebo) [40]).

Topiramate has also proven efficacious in patients with chronic migraine [47, 48]. In two randomized, placebo-controlled, double-blinded studies with 387 subjects with a daily dose of $100 \mathrm{mg}$ or $50-200 \mathrm{mg}$ topiramate showed a significant reduction in monthly migraine days compared to placebo $(-6.4( \pm 5.8)$ vs. -4.7 $( \pm 6.1)$ [47] and $-3.5( \pm 6.3)$ vs. $+0.2( \pm 4.7)$ [48]). The $\geq 50 \%$ responder rate was also significantly higher for topiramate ( $22 \%$ vs. $0 \%$ for placebo) [48]. In line with this, blocking of CGRP significantly reduced the number 
of monthly headache migraine days in 1113 chronic migraine patients with an average of 19.4 headache days $(-4.8(120 \mathrm{mg}) /-4.6(240 \mathrm{mg})$ vs. -2.7 (placebo)). Likewise, the $\geq 50 \%$ responder rate was significantly higher for the active drug compared to placebo. (27.6\% (120 mg)/ 27.5\% (240 mg) vs. 15.4\%) [49].

Another important aspect of medication is the incidence and severity of adverse events. Compared to topiramate, adverse events reported from CGRP trials were generally mild and less frequent. Upper respiratory tract infection/nasopharyngitis, and injection-site pain have so far been the most frequent reported adverse events [4043] (see next paragraph for more details). In contrast, reported adverse events of topiramate, such as taste disturbance, weight loss, anorexia, fatigue, memory problems and paresthesia were more common in the active groups than in the placebo groups.

\section{Safety issues regarding blocking of CGRP - Are there any?}

\section{Evidence from clinical studies}

Even though the knowledge of the presence and function of CGRP in the CNS is sparse, the function in both the peripheral and enteric nervous system is well established and CGRP is expressed widely throughout both systems. Thus, a wide variety of possible adverse events could be anticipated when blocking CGRP. However, reported adverse events after blocking of CGRP have in general been mild to moderate and the incidences have been low.

Among the first CGRP receptor antagonists under trial, intravenous olcegepant caused mild to moderate adverse events such as paresthesia, nausea, headache, dry mouth and unspecific vision disturbances in a minority of patients [18]. However, more serious adverse events were reported with telcagepant and MK-3207, which caused liver toxicity with transient increase of transaminases in a small group of included subjects ( $n=13$ for telcagepant) upon repeated doses. This lead to discontinuation of the trial program for these molecules $[15,25]$. Other non-peptide CGRP receptor antagonists such as BI44370TA, BMS-927711, and, most recently, MK-1602 have also been tested. For all three molecules adverse events were mild to moderate and the incidence was low and similar to the placebo group [21, 30, 33]. No liver toxicity was reported for these drugs, and the gepant program is thus still ongoing.

More recently, great attention has been given to the development and testing of monoclonal antibodies (mABs) targeting circulating CGRP or its receptors. Most importantly, none of these drugs show liver toxicity. This is in line with the theoretical probability of $\mathrm{mABs}$ causing liver toxicity, which is very low, since metabolism of $\mathrm{mABs}$ do not result in production of toxic metabolites [50]. In addition, despite the potentially harmful inhibition of vasodilation due to CGRP inhibition, no cardiovascular concerns have been disclosed with any of these drugs [51]. In trials, eptinezumab, galcanezumab and fremanezumab, monoclonal antibodies which all target CGRP, showed variable percentages of adverse events, which in line with the gepants, were mild to moderate (e.g. upper respiratory or urinary tract infection, fatigue, back pain, arthralgia, nausea and vomiting). Erenumab (AMG 334), which binds to the CGRP receptor, was also safe and well tolerated in a phase 2 trial [31].

In line with the poor chance of both the non-peptide CGRP receptor antagonists and the antibodies crossing the blood-brain barrier (BBB) [52], no central side effects have been reported so far. Therefore, although crossing of the BBB is likely to occur to some extent - telcagepant has been detected in primates cerebrospinal fluid, suggesting its presence in the CNS [53] - a central effect - and side effect - of these drugs seems unlikely.

\section{Do preclinical studies give reason to be concerned about side effects?}

CGRP is an ubiquitous peptide that is not only involved in migraine, but also in several physiological processes [12] and in homeostatic responses during pathophysiological conditions (Fig. 3) [9, 12]. As such, it is vital to consider the possible side effects caused by the nonselective blockade of $\alpha$ - and $\beta$-CGRP with the CGRP (receptor)-antibodies. As discussed in the previous section, the adverse events of the Phase II trials were mild [31, 32, 34-37], but it should be noted that the duration of these trials is not sufficient to see the long-term effects of continuingly blocking CGRP or its receptor.

In the cardiovascular system, CGRP is present in nerve fibers that innervate blood vessels [54] and the heart [55, 56], and participates in the regulation of blood pressure [12, 57-59]. Furthermore, it has also been described to have a role in the maintenance of (cardio)vascular homeostasis during ischemic events [9] and in tissue remodeling in pulmonary hypertension [60]. This protective role raises a concern, since migraine patients present an increased cardiovascular risk $[61,62]$. This topic was recently reviewed elsewhere [9]. Hence, it is important to consider preexisting cardiovascular risk factors in patients (i.e. family history, tobacco exposure, obesity) to prevent a possible cardiovascular event.

Although CGRP participates in inflammatory processes [63-65], it has also been associated with facilitation of wound healing [66]. This is thought to be mediated through its ability to promote keratinocytes proliferation [67], enhance revascularization [68], reduce expression of tumor necrosis factor- $\alpha$ (TNF- $\alpha$ ) and attenuate macrophage infiltration [69]. A consequence of blocking CGRP could thus be alterations in wound 


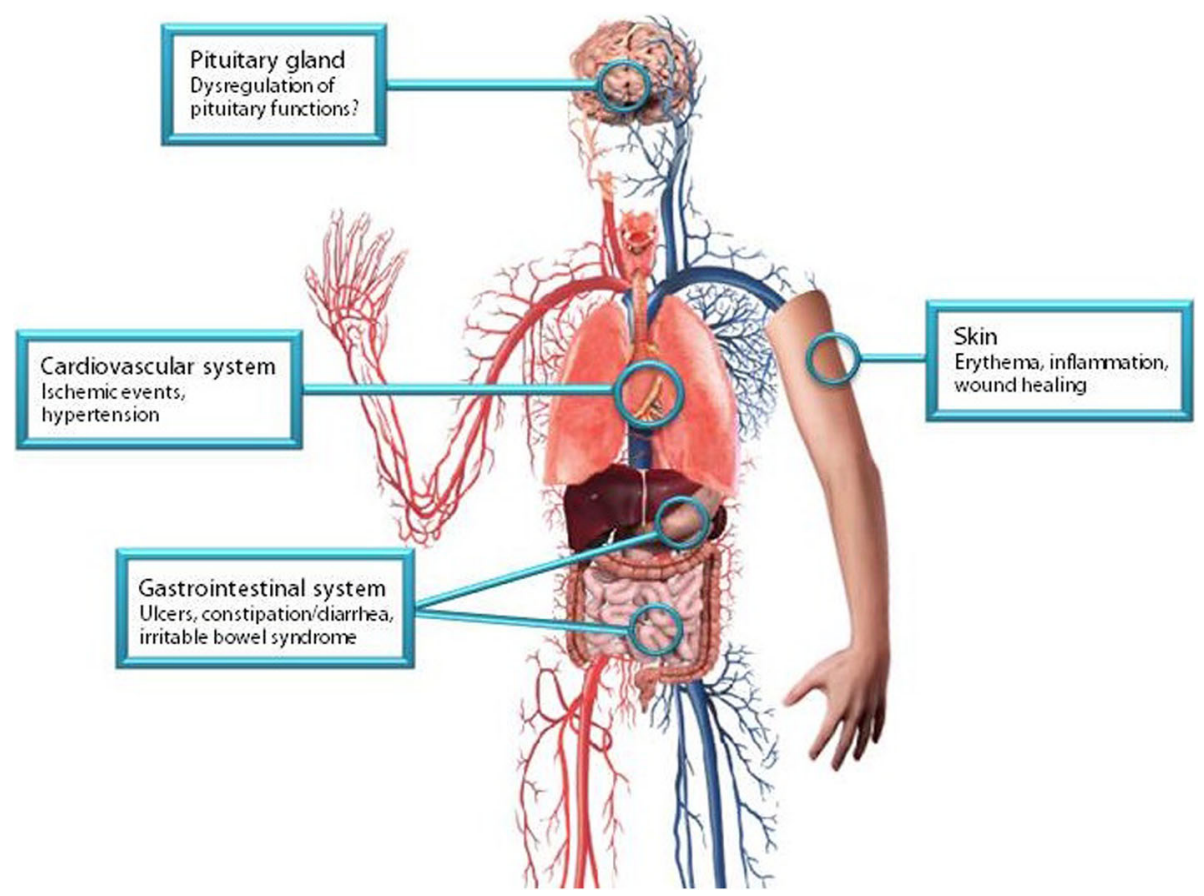

Fig. 3 Possible side effects after long-term exposure to CGRP (receptor)-antibodies. An overview of the organ systems where CGRP and the receptor are present and possible side effects that could be caused by the non-selective blockade of $a$ - and $\beta$-CGRP with the CGRP (receptor)-antibodies

healing and increased inflammatory responses in skin injuries at the site of injection for the antibodies. However, this is a theoretical risk which has so far not been observed in clinical trials.

The antibodies against CGRP are not selective for $\alpha$ CGRP but also block $\beta$-CGRP. The gastrointestinal tract is highly innervated by $\beta$-CGRPergic fibers from the enteric nervous system [70, 71]. In fact, animal studies with antibodies against CGRP showed extensive mucosal damage $[72,73]$, suggesting a role of CGRP in maintaining the mucosal integrity of the gastrointestinal tract. Blocking this could thus contribute to inflammatory bowel disease. Gastrointestinal motility is also considered to be modulated by CGRP, and administration of this peptide induces a dose-dependent biphasic response [74], which could lead to episodes of diarrhea or constipation. Furthermore, studies with CGRP KO mice have suggested CGRP agonists as a possible treatment for ulcer healing [75]; therefore, monitoring of gastrointestinal complications (i.e. ulcers, constipation) is recommended, even though 12 week studies have not reported these.

Finally, since it, as mentioned, is unlikely that the antibodies cross the BBB - and unlikely that the BBB penetration is changed during migraine attacks $[76,77]-$ it is important to consider the structures from CNS that are not protected by the BBB. Recent studies have demonstrated that the TG, together with the pituitary, are outside the BBB [78]. An effect on the TG could thus, partly, explain the therapeutic effect of the antibodies. However, CGRP and its receptor are also expressed in the anterior pituitary, suggesting a possible involvement in the regulation of hypothalamo-pituitary tract functions [79]. The exact involvement is still unknown, and further studies are needed to determine the long-term effects of blocking CGRP on the homeostatic functions of the pituitary hormones.

\section{Other considerations}

Even though blocking of CGRP seems to be an efficacious and safe preventative treatment of migraine, there are many other aspects to consider with regards to the pros and cons of blocking CGRP in migraine patients.

Firstly, the administration of the newly developed monoclonal antibodies is either intravenous or subcutaneous. This could potentially cause complications at the injection site, and common adverse events in those treated with fremanezumab, galcanezumab and erenumab were indeed mild injection-site pain, pruritus and erythema [80]. A disadvantage of the intravenous administration route is the need of it being administered by a medical doctor. This not only increases the placebo response in clinical trials, but does also require for the patient to spend time visiting the clinic - increasing the risk of pathologization of the patient. However, the monthly administration, which is feasible due to the long half-lives of the medication, could improve adherence 
and compliance to medication, which is a common problem in treating migraine $[81,82]$. Additionally, the CGRP antibodies seem to show a low risk for drug-drug interactions and hepatotoxicity since they are metabolized by degradation into peptides and single amino acids [83], which could be important for patients using multiple medications.

Secondly, as mentioned, the long-term risks of blocking CGRP are still unknown. Even though the absence of liver toxicity or other abnormalities in routine blood testing is in support of no or low long-term risks [80], studies testing the cardiovascular safety of the long-term blockade are warranted in order to answer the numerous questions on the possibility of higher risk in cardio- and cerebrovascular compromised patients. For example, it is unknown whether blocking CGRP could potentially transform transient mild cerebral ischemia into a fullblown brain infarct [9] and whether these risks are higher in women $[9,84]$. To investigate these aspects, future studies should include patients with preexisting cardiovascular conditions.

Thirdly, the exact site of action of blocking CGRP is still partly unknown and CGRP could exert its effects on receptors distinct from the CGRP receptor [9]. Recently it was put forward that CGRP may act on the amylin receptor in TG [85] as well as in human coronary arteries [86]. If this is the case, this could pose an additional unknown - potential risk of wiping out CGRP. We can also only guess whether patients not benefitting from receptor blockade would benefit from blockage of the peptide itself. Future studies should investigate how to differentiate responders from non-responders.

Lastly, a disadvantage when using antibodies is the risk of development of antibodies against the drug [15]. Indeed, antidrug antibodies were detected with all four antibodies [80], but these did not seem to affect efficacy [31]. However, long-term studies are needed to investigate whether, at long term, neutralizing antidrug antibodies will pose a problem for efficacy and safety of blocking CGRP with monoclonal antibodies. Finally, it is well known that antibody treatment is costly and the price of the drugs has to be taken into consideration when deciding whether to use CGRP antibodies as a prophylactic treatment and which patient groups to treat.

\section{Conclusion}

Here, we have reviewed the pros and cons of blocking CGRP in migraine patients. In favor of using blocking of CGRP as a treatment of migraine, is that - based on evidence from clinical trials - whether using small molecule receptor antagonists or antibodies, the treatment is efficacious. Additionally, the liver toxicity induced by some of the gepants is not present with the antibodies, which are well tolerated. Lastly, in contrast to current prophylactic treatments, the drugs are developed specifically for migraine, based on findings from human migraine studies. Thus, the drugs may exert a more direct effect on migraine specific pathways than previously used prophylactic drugs. In addition, this provides hope and encouragement for further research into the pathophysiological mechanisms of migraine and potentially the discovery of other migraine specific therapeutic targets.

Speaking against chronically blocking CGRP, the longterm effects, particularly regarding the cardiovascular risks, are still unknown as well as the exact mode of action of the antibodies. In addition, development of neutralizing antidrug antibodies may, with time, affect the efficacy of the antibodies. Lastly, as with all antibody therapies, CGRP antibodies have the problem of being costly. However, taking into consideration the enormous socioeconomically burden that migraine is [87], the price may be well payed off.

In conclusion, based on current knowledge, we believe that the benefits of blocking CGRP - including the perspectives of improving the lives of those suffering from frequent headaches - seems to be greater than the disadvantages.

\section{Acknowledgements \\ The European Headache Federation and the Department of Clinical and Molecular Medicine, Sapienza University of Rome, are gratefully acknowledged for supporting this work.}

\section{Author's contributions}

LE and AM conceived the review. All authors designed the review, drafted the manuscript and revised it for intellectual content. All authors read and approved the final manuscript.

\section{Funding}

This work was supported by the European Headache Federation.

Ethics approval and consent to participate

Not applicable

\section{Consent for publication}

Not applicable

\section{Competing interests}

AMvdB received research grants from Amgen/Novartis. LE has given talks and received grant for preclinical studies sponsored by Novartis and TEVA. All other authors declare no conflicts of interest.

\section{Publisher's Note}

Springer Nature remains neutral with regard to jurisdictional claims in published maps and institutional affiliations.

\section{Author details}

'Danish Headache Center, Department of Neurology, Rigshospitalet, Copenhagen, Denmark. ${ }^{2}$ Department of Child Neuropsychiatry, University of Palermo, Palermo, Italy. ${ }^{3}$ Department of Neurology, University Hospital, LMU, Munich, Germany. ${ }^{4}$ Department of Neurology, Ghent University Hospital, Ghent, Belgium. ${ }^{5}$ Headache Center, Bambino Gesù Children's Hospital, IRCCS, Rome, Italy. ${ }^{6}$ Division of Vascular Medicine and Pharmacology, Department of Internal Medicine, Erasmus University Medical Center, Rotterdam, The Netherlands. ${ }^{7}$ Department of Experimental Biomedicine and Clinical Neurosciences, University of Palermo; Advanced Algology Research and Pain Medicine Unit, Santa Maria Maddalena Hospital, Occhiobello, Italy.

${ }^{8}$ Department of Internal Medicine, Institute of Clinical Sciences, Lund University, Lund, Sweden. 
Received: 26 July 2017 Accepted: 14 September 2017 Published online: 25 September 2017

\section{References}

1. Edvinsson $L$ (1985) Functional role of perivascular peptides in the control of cerebral circulation. Trends Neurosci 2:2-7

2. Goadsby PJ, Edvinsson L (1993) The trigeminovascular system and migraine: studies characterizing cerebrovascular and neuropeptide changes seen in humans and cats. Ann Neurol 33:48-56. doi:10.1002/ana.410330109

3. Goadsby PJ, Edvinsson L (1994) Peripheral and central Trigeminovascular activation in cat is blocked by the serotonin (5HT)-I D receptor agonist 311C90. Headache J Head Face Pain 34:394-399. doi:10.1111/j.1526-4610. 1994.hed3407394.x

4. Lassen LH, Haderslev PA, Jacobsen VB et al (2002) CGRP may play a causative role in migraine. Cephalalgia 22:54-61. doi:10.1046/j.1468-2982. 2002.00310.x

5. Uddman R, Edvinsson L, Ekman R et al (1985) Innervation of the feline cerebral vasculature by nerve fibers containing calcitonin gene-related peptide: trigeminal origin and co-existence with substance P. Neurosci Lett 62:131-136. doi:10.1016/0304-3940(85)90296-4

6. Edvinsson $L$ (2015) CGRP receptor antagonists and antibodies against CGRP and its receptor in migraine treatment. Br J Clin Pharmacol 80:193-199. doi:10.1111/bcp.12618

7. Eftekhari S, Warfvinge K, Blixt FW, Edvinsson L (2013) Differentiation of nerve fibers storing CGRP and CGRP receptors in the peripheral trigeminovascular system. J Pain 14:1289-1303. https://doi.org/10.1016/j.jpain.2013.03.010

8. Eftekhari S, Edvinsson L (2010) Possible sites of action of the new calcitonin gene-related peptide receptor antagonists. Ther Adv Neurol Disord 3:369378. https://doi.org/10.1177/1756285610388343

9. MaassenVanDenBrink A, Meijer J, Villalón CM, Ferrari MD (2016) Wiping out CGRP: potential cardiovascular risks. Trends Pharmacol Sci 37:779-788. https://doi.org/10.1016/j.tips.2016.06.002

10. Schou WS, Ashina S, Amin FM et al (2017) Calcitonin gene-related peptide and pain: a systematic review. J Headache Pain 18:34. doi:10.1186/s10194017-0741-2

11. Edvinsson L, Linde M (2010) New drugs in migraine treatment and prophylaxis: Telcagepant and topiramate. Lancet 376:645-655. doi:10.1016/ S0140-6736(10)60323-6

12. Russell FA, King R, Smillie S-J et al (2014) Calcitonin gene-related peptide: physiology and Pathophysiology. Physiol Rev 94:1099-1142. doi:10.1152/ physrev.00034.2013

13. Doods H, Hallermayer G, Wu D et al (2000) Pharmacological profile of BIBN4096BS, the first selective small molecule CGRP antagonist. Br J Pharmacol 129:420-423. doi:10.1038/sj.bjp.0703110

14. Vécsei L, Szok D, Csáti A, Tajti J (2015) CGRP antagonists and antibodies for the treatment of migraine. Expert Opin Investig Drugs 24:31-41. doi:10.1517/13543784.2015.960921

15. Bigal ME, Walter S, Rapoport AM (2013) Calcitonin gene-related peptide (CGRP) and migraine current understanding and state of development. Headache 53:1230-1244. doi:10.1111/head.12179

16. Juhl L, Edvinsson L, Olesen J, Jansen-Olesen I (2007) Effect of two novel CGRP-binding compounds in a closed cranial window rat model. Eur J Pharmacol 567:117-124. doi:10.1016/j.ejphar.2007.04.004

17. Edvinsson L, Nilsson E, Jansen-Olesen I (2007) Inhibitory effect of BIBN4096BS, CGRP(8-37), a CGRP antibody and an RNA-Spiegelmer on CGRP induced vasodilatation in the perfused and non-perfused rat middle cerebral artery. BrJPharmacol 150:633-640. doi:10.1038/sj.bjp.0707134

18. Olesen J, Diener H, Husstedt IW, et al (2004) Calcitonin gene-related peptide receptor antagonist BIBN 4096 BS for the acute treatment of migraine. Society 1104-1110

19. Connor KM, Aurora SK, Loeys T et al (2011) Long-term tolerability of telcagepant for acute treatment of migraine in a randomized trial. Headache 51:73-84. doi:10.1111/j.1526-4610.2010.01799.x

20. Connor KM, Shapiro RE, Diener H-C et al (2009) Randomized, controlled trial of telcagepant for the acute treatment of migraine. Neurology 73:970-977

21. Diener H-C, Barbanti P, Dahlöf C et al (2011) Bl 44370 TA, an oral CGRP antagonist for the treatment of acute migraine attacks: results from a phase II study. Cephalalgia 31:573-584. doi:10.1177/0333102410388435

22. Hewitt DJ, Aurora SK, Dodick DW et al (2011) Randomized controlled trial of the CGRP receptor antagonist MK-3207 in the acute treatment of migraine. Cephalalgia 31:712-722. doi:10.1177/0333102411398399
23. Hewitt DJ, Martin V, Lipton RB et al (2011) Randomized controlled study of telcagepant plus ibuprofen or acetaminophen in migraine. Headache 51: 533-543. doi:10.1111/j.1526-4610.2011.01860.x

24. Ho AP, Dahlöf CG, Silberstein SD et al (2010) Randomized, controlled trial of telcagepant over four migraine attacks. Cephalalgia 30:1443-1457. doi:10. $1177 / 0333102410370878$

25. Ho TW, Connor KM, Zhang Y et al (2014) Randomized controlled trial of the CGRP receptor antagonist telcagepant for migraine prevention. Neurology 83:958-966. doi:10.1212/WNL.0000000000000771

26. Ho TW, Ferrari MD, Dodick DW et al (2008) Efficacy and tolerability of MK0974 (telcagepant), a new oral antagonist of calcitonin gene-related peptide receptor, compared with zolmitriptan for acute migraine: a randomised, placebo-controlled, parallel-treatment trial. Lancet 372:2115-2123. doi:10. 1016/S0140-6736(08)61626-8

27. Ho TW, Ho AP, Chaitman BR et al (2012) Randomized, controlled study of telcagepant in patients with migraine and coronary artery disease. Headache 52:224-235. doi:10.1111/j.1526-4610.2011.02052x

28. Ho TW, Ho AP, Ge Y (Joy), et al (2016) Randomized controlled trial of the CGRP receptor antagonist telcagepant for prevention of headache in women with perimenstrual migraine. Cephalalgia 36:148-161. doi: 10.1177/ 0333102415584308

29. Ho TW, Mannix LK, Fan X et al (2008) Randomized controlled trial of an oral CGRP receptor antagonist, MK-3207, in the acute treatment of migraine. Neurology 70:1304-1312. doi:10.1177/0333102411398399

30. Marcus R, Goadsby PJ, Dodick D et al (2014) BMS-927711 for the acute treatment of migraine: a double-blind, randomized, placebo controlled, dose-ranging trial. Cephalalgia 34:114-125. doi:10.1177/0333102413500727

31. Sun H, Dodick DW, Silberstein S et al (2016) Safety and efficacy of AMG 334 for prevention of episodic migraine: a randomised, double-blind, placebocontrolled, phase 2 trial. Lancet Neurol 15:382-390. doi:10.1016/S14744422(16)00019-3

32. Tepper S, Ashina M, Reuter U, et al (2017) Safety and efficacy of erenumab for preventive treatment of chronic migraine: a randomised, double-blind, placebo-controlled phase 2 trial. doi: 10.1016/S1474-4422(17)30083-2

33. Voss T, Lipton RB, Dodick DW et al (2016) A phase Ilb randomized, doubleblind, placebo-controlled trial of ubrogepant for the acute treatment of migraine. Cephalalgia 36:887-898. doi:10.1177/0333102416653233

34. Dodick DW, Goadsby PJ, Silberstein SD et al (2014) Safety and efficacy of ALD403, an antibody to calcitonin gene-related peptide, for the prevention of frequent episodic migraine: a randomised, double-blind, placebocontrolled, exploratory phase 2 trial. Lancet Neurol 13:1100-1107. doi:10. 1016/S1474-4422(14)70209-1

35. Dodick DW, Goadsby PJ, Spierings ELH et al (2014) Safety and efficacy of LY2951742, a monoclonal antibody to calcitonin gene-related peptide, for the prevention of migraine: a phase 2, randomised, double-blind, placebocontrolled study. Lancet Neurol 13:885-892. doi:10.1016/S14744422(14)70128-0

36. Bigal ME, Dodick DW, Rapoport AM et al (2015) Safety, tolerability, and efficacy of TEV-48125 for preventive treatment of high-frequency episodic migraine: a multicentre, randomised, double-blind, placebo-controlled, phase 2b study. Lancet Neurol 14:1081-1090. doi:10.1016/S14744422(15)00249-5

37. Bigal ME, Edvinsson L, Rapoport AM et al (2015) Safety, tolerability, and efficacy of TEV-48125 for preventive treatment of chronic migraine: a multicentre, randomised, double-blind, placebo-controlled, phase $2 b$ study. Lancet Neurol 14:1091-1100. doi:10.1016/S1474-4422(15)00245-8

38. D'Amico D, Tepper SJ (2008) Prophylaxis of migraine: General principles and patient acceptance. Neuropsychiatr Dis Treat 4:1155-1167. doi:10.2147/NDT. S3497.

39. Silberstein SD, Holland S, Freitag F, et al. (2012) Evidence-based guideline update: pharmacologic treatment for episodic migraine prevention in adults. Neurology 78:1337-45. doi:10.1212/WNL.0b013e3182535d20.

40. Lilly's Galcanezumab Significantly Reduces Number of Migraine Headache Days for Patients with Migraine: New Results Presented at AHS (NYSE:LLY). https://investor.lilly.com/releasedetail.cfm?releaseid=1029791. Accessed 21 Aug 2017

41. Alder BioPharmaceuticals Announces Positive Eptinezumab Phase 3 Results for Prevention of Frequent Episodic Migraine (NASDAQ:ALDR). http://investor. alderbio.com/releasedetail.cfm?releaseid=1031418. Accessed 21 Aug 2017

42. Teva's Fremanezumab Meets all Primary and Secondary Endpoints Across Both Monthly and Quarterly Dosing Regimens in Phase III Study in Episodic 
Migraine Prevention. http://www.tevapharm.com/news/teva_s_ fremanezumab_meets_all_primary_secondary_endpoints_across_both_ monthly_and_quarterly_dosing_regimens_in_phase_iii_study_in_episodic_ migraine_prevention_06_17.aspx. Accessed 21 Aug 2017

43. Novartis announces Phase III study shows AMG 334 significantly reduces monthly migraine days in people with episodic migraine | Novartis. https:// www.novartis.com/news/media-releases/novartis-announces-phase-iii-studyshows-amg-334-significantly-reduces-monthly. Accessed 21 Aug 2017

44. Brandes J, Saper J, Diamond M et al (2004) Topiramate for migraine prevention: a randomized controlled trial. JAMA 291:965-973. doi:10.1592/ phco.26.3.375

45. Diener H-C, Tfelt-Hansen P, Dahlöf C et al (2004) Topiramate in migraine prophylaxis results from a placebo-controlled trial with propranolol as an active control. J Neurol 251:943-950. doi:10.1007/s10072-005-0425-6

46. Silberstein SD, Standnes B, Kangasneimi P, et al (2004) Topiramate in migraine prevention. Arch Neurol 61:490-495. doi:10.1001/archneur.61.4.490

47. Silberstein SD, Lipton RB, Dodick DW et al (2007) Efficacy and safety of topiramate for the treatment of chronic migraine: a randomized, doubleblind, placebo-controlled trial. Headache 47:170-180. doi:10.1111/j.15264610.2006.00684.x

48. Diener HC, Bussone G, Van Oene JC et al (2007) Topiramate reduces headache days in chronic migraine: a randomized, double-blind, placebo-controlled study. Cephalalgia 27:814-823. doi:10.1111/j.1468-2982.2007.01326.x

49. Lilly Announces Positive Results for Three Phase 3 Studies of Galcanezumab for the Prevention of Episodic and Chronic Migraine (NYSE:LLY). https:// investor.lilly.com/releasedetail.cfm?releaseid=1026201. Accessed 21 Aug 2017.

50. Wang W, Wang EQ, Balthasar JP (2008) Monoclonal antibody pharmacokinetics and pharmacodynamics. Clin Pharmacol Ther 84:548-558. doi:10.1038/clpt.2008.170

51. Bigal ME, Walter S, Rapoport AM (2015) Therapeutic antibodies against CGRP or its receptor. Br J Clin Pharmacol 79:886-895. doi:10.1111/bcp.12591

52. lyengar S, Ossipov MH, Johnson KW (2016) The role of CGRP in peripheral and central pain mechanisms including migraine. Pain 158:543-559. doi:10.1097/j.pain.0000000000000831

53. Sur C, Hargreaves RJ, Bell IM et al (2009) CSF levels and binding pattern of novel CGRP receptor antagonists in rhesus monkey and human central nervous system: toward the development of a PET tracer. Cephalalgia 29:136-137

54. Uddman R, Edvinsson L, Ekblad E et al (1986) Calcitonin gene-related peptide (CGRP): perivascular distribution and vasodilatory effects. Regul Pept 15:1-23. doi:10.1016/0167-0115(86)90071-6

55. Wimalawansa J, Maclntyre I (1988) Calcitonin gene-related peptide and its specific binding sites in the cardiovascular system of rat. Int I Cardiol 20:29-37

56. Opgaard OS, Gulbenkian S, Bergdahl A et al (1995) Innervation of human epicardial coronary veins: immunohistochemistry and vasomotility. Cardiovasc Res 29:463-468

57. Lindstedt IH, Edvinsson M-L, Edvinsson L (2006) Reduced responsiveness of cutaneous microcirculation in essential hypertension-a pilot study. Blood Press 15:275-280. doi:10.1080/08037050600996586

58. McCulloch J, Uddman R, Kingman TA, Edvinsson L (1986) Calcitonin generelated peptide: functional role in cerebrovascular regulation. Proc Natl Acad Sci U S A 83:5731-5735. doi:10.1073/pnas.83.15.5731

59. Edvinsson L, Uddman R, Mulder H (1998) Calcitonin gene-related peptide and nitric oxide in the trigeminal ganglion: cerebral vasodilation from trigeminal nerve stimulation involves mainly calcitonin gene-related peptide. J Aut Nerv Syst 70:15-22

60. Keith IM, Tjen AL, Kraiczi H, Ekman R (2000) Three-week neonatal hypoxia reduces blood CGRP and causes persistent pulmonary hypertension in rats. AmJPhysiolHeart CircPhysiol 279:H1571-H1578

61. Sacco S, Kurth T (2014) Migraine and the risk for stroke and cardiovascular disease. Curr Cardiol Rep 16:1-7. doi:10.1007/s11886-014-0524-1

62. Kurth T, Winter AC, Eliassen AH et al (2016) Migraine and risk of cardiovascular disease in women: prospective cohort study. BMJ 253:i2610 doi:10.1136/bmj.i2610

63. Salmona M, Damaj Mi, Marubio Lm, et al (2001) Altered neuroadaptation in opiate dependence and neurogenic inflammatory nociception in alpha CGRP-deficient mice. Nat Neurosci 4:357-358. doi: 10.1100/tsw.2001.439

64. Zhang L, Hoff AO, Wimalawansa SJ et al (2001) Arthritic calcitonin/a calcitonin gene-related peptide knockout mice have reduced nociceptive hypersensitivity. Pain 89:265-273. doi:10.1016/S0304-3959(00)00378-X
65. Benschop RJ, Collins EC, Darling RJ et al (2014) Development of a novel antibody to calcitonin gene-related peptide for the treatment of osteoarthritisrelated pain. Osteoarthr Cartil 22:578-585. doi:10.1016/j.joca.2014.01.009

66. Khalil Z, Helme R (1996) Sensory peptides as Neuromodulators of wound healing in aged rats. J Gerontol Ser A Biol Sci Med Sci 51A:B354-B361. doi:10.1093/gerona/51A.5.B354

67. Roggenkamp D, Köpnick S, Stäb F et al (2013) Epidermal nerve fibers modulate Keratinocyte growth via Neuropeptide signaling in an innervated skin model. J Invest Dermatol 133:1620-1628. doi:10.1038/jid.2012.464

68. Mishima T, Ito Y, Hosono K et al (2011) Calcitonin gene-related peptide facilitates revascularization during hindlimb ischemia in mice. Am J Physiol Circ Physiol 300:H431-H439. doi:10.1152/ajpheart.00466.2010

69. Zhang X, Zhuang J, Wu H et al (2010) Inhibitory effects of Calcitonin generelated peptides on experimental vein graft disease. Ann Thorac Surg 90: 117-123. doi:10.1016/j.athoracsur.2010.03.063

70. Mulderry PK, M A G, R a S et al (1988) Differential expression of alpha-CGRP and beta-CGRP by primary sensory neurons and enteric autonomic neurons of the rat. Neuroscience 25:195-205. doi:10.1016/0306-4522(88)90018-8

71. STERNINI C (1992) Enteric and visceral afferent CGRP neurons: targets of Innervation and differential expression patterns. Ann N Y Acad Sci 657:170186. doi: 10.1111/j.1749-6632.1992.tb22766.x

72. Peskar BM, Wong HC, Walsh JH, Holzer P (1993) A monoclonal antibody to calcitonin gene-related peptide abolishes capsaicin-induced gastroprotection. Eur J Pharmacol 250:201-203. doi:10.1016/00142999(93)90645-X

73. Reinshagen M, Flämig G, Ernst S et al (1998) Calcitonin gene-related peptide mediates the protective effect of sensory nerves in a model of colonic injury. J Pharmacol Exp Ther 286:657-661

74. Bartho L, Koczan G, Maggi CA (1993) Studies on the mechanism of the contractile action of rat calcitonin gene-related peptide and of capsaicin on the guinea-pig lleum: effect of hCGRP (8-37) and CGRP tachyphylaxis. Neuropeptides 25:325-329. doi:10.1016/0143-4179(93)90051-B

75. Ohno T, Hattori Y, Komine R et al (2008) Roles of Calcitonin gene-related peptide in maintenance of gastric mucosal integrity and in enhancement of ulcer healing and angiogenesis. Gastroenterology 134:215-225. doi:10.1053/ j.gastro.2007.10.001

76. Schankin CJ, Maniyar FH, Seo Y et al (2016) Ictal lack of binding to brain parenchyma suggests integrity of the blood-brain barrier for 11Cdihydroergotamine during glyceryl trinitrate-induced migraine. Brain 139: 1994-2001. doi:10.1093/brain/aww096

77. Hougaard A, Amin FM, Christensen CE et al (2017) Increased brainstem perfusion, but no blood-brain barrier disruption, during attacks of migraine with aura. Brain 140:1-10. doi:10.1093/brain/awx089

78. Eftekhari S, Salvatore CA, Johansson S et al (2015) Localization of CGRP, CGRP receptor, PACAP and glutamate in trigeminal ganglion. Relation to the bloodbrain barrier. Brain Res 1600:93-109. doi:10.1016/j.brainres.2014.11.031

79. Wimalawansa SJ, El-Kholy AA (1993) Comparitive study of distribution and biochemical characterization of brain calcitonin gene-related peptide receptors in five different species. Neuroscience 54:513-519

80. Mitsikostas DD, Reuter U (2017) Calcitonin gene-related peptide monoclonal antibodies for migraine prevention : comparisons across randomized controlled studies. Curr Opin Neurol 30:272-280. doi:10.1097/NCO.0000000000000438

81. Hepp Z, Dodick DW, Varon SF et al (2015) Adherence to oral migrainepreventive medications among patients with chronic migraine. Cephalalgia 35:478-488. doi:10.1177/0333102414547138

82. Hepp Z, Bloudek LM, Varon SF (2014) Systematic review of migraine prophylaxis adherence and persistence. J Manag Care Pharm 20:22-33

83. Zhou H, Mascelli MA (2011) Mechanisms of monoclonal antibody-drug interactions. Annu Rev Pharmacol Toxicol 51:359-372. doi:10.1146/annurevpharmtox-010510-100510

84. Gangula PRR, Wimalawansa SJ, Yallampalli C (2002) Sex steroid hormones enhance Hypotensive effects of Calcitonin gene-related peptide in aged female rats. Biol Reprod 67:1881-1887. doi:10.1095/biolreprod.102.007682

85. Walker CS, Eftekhari S, Bower RL et al (2015) A second trigeminal CGRP receptor: function and expression of the AMY1 receptor. Ann Clin Transl Neurol 2:595-608. doi:10.1002/acn3.197

86. Haanes KA, Chan KY, MaassenVanDenBrink A (2016) Comment on "a second trigeminal CGRP receptor: function and expression of the AMY1 receptor.". Ann Clin Transl Neurol 3:307-308. doi:10.1002/acn3.286

87. Estemalik E, Tepper S (2013) Preventive treatment in migraine and the new US guidelines. Neuropsychiatr Dis Treat 9:709-720. doi:10.2147/NDT.S33769 